\title{
E-Portfolios for Integrated Reflection
}

\author{
Shouhong Wang \\ University of Massachusetts Dartmouth, MA, USA
}

\author{
swang@umassd.edu
}

\begin{abstract}
E-portfolios have been widely used in the education community. Currently, e-portfolios are viewed mostly as a tool of assessment and showcase, but less as a tool of active learning. This paper proposes an ontological model that specifies a generic organizational structure of eportfolios in the integrated reflection context. An example of design artifact of ontology of eportfolios is used to illustrate the concepts of the development and use of e-portfolios for active learning through reflection.
\end{abstract}

Keywords: E-portfolios, integrated reflection, learning object, ontology, design research.

\section{Introduction}

Recently more and more students and teachers are using e-portfolio systems. There will be massive pieces of electronic portfolio artifacts stored in those systems. E-portfolios are supposed to serve three purposes: assessment, showcase, and learning (Greenberg, 2004). For assessment purposes, e-portfolios include rubrics-based documentations and feedback from teachers. For showcase purposes, e-portfolios present artifacts of accomplishments and lifelong career development. For learning purposes, e-portfolios can be useful for on-going reflection. The current commercial or open source e-portfolio systems have been successfully used for assessment and showcase, but have not been effectively applied to enhancing students' learning (Zhang, Olfman, $\&$ Rectham, 2007). This is mainly because generic e-portfolio systems are more or less learning domain (or subject) independent. On the other hand, useful learning portfolios must be learning domain specific. This challenge raises a significant research question: how e-portfolios can be used as a learning tool for students thinking. To make generic e-portfolio systems more useful for enhancing students' thinking, a layer of e-portfolio system must be developed to facilitate students' integrated reflection. In this study, reflection is higher-order thinking for a purpose such as learning what one has learned. Integrated reflection is active higher-order thinking process cross the boundaries between topics, courses, or even disciplines.

This paper proposes an ontological model that specifies a generic organizational structure of eportfolios in the integrated reflection context. The ultimate objective of this study is to make contribution to information systems design

Material published as part of this publication, either on-line or in print, is copyrighted by the Informing Science Institute. Permission to make digital or paper copy of part or all of these works for personal or classroom use is granted without fee provided that the copies are not made or distributed for profit or commercial advantage AND that copies 1) bear this notice in full and 2) give the full citation on the first page. It is permissible to abstract these works so long as credit is given. To copy in all other cases or to republish or to post on a server or to redistribute to lists requires specific permission and payment of a fee. Contact Publisher@InformingScience.org to request redistribution permission. science (Gregor 2006; Gregor \& Jones 2007; Hevner, March, Park, \& Ram, 2004; Walls, Widmeyer, \& El Sawy, 1992) through the demonstration of an information system artifact for eportfolio systems. 


\section{Related Work}

\section{E-Portfolios}

A portfolio is a systematic and purposeful collection of work and achievement documentations (Drier, 1997). E-portfolios are highly personalized, customizable, Web-based files which document learning portfolios and demonstrate individual and collaborative learning process (McCowan, Harper, \& Hauville, 2005). An e-portfolio system is a Web-based repository management system that stores students' learning documents (known under the name of artifacts) such as academic records, essays, project reports, assignments, assessments, and personal and professional development related contents. Students use e-portfolio systems to present artifacts, receive feedback from instructors and advisors, and communicate with each other.

There are many commercial, non-profit organizational, and open-source e-portfolio systems, such as Chalk \& Wire (CW, 2009), KEEP toolkit (KEEP, 2009), foliotek (2009), TaskStream (2009), and Open-Source Portfolio (OSP) (OSP, 2005). While there are high variations of user interface design among these e-portfolio systems, the functiona lities of current competitive e-portfolio systems are about the same and include artifacts editing and uploading, commenting and assessing on student work, communicating and sharing within groups, showcase generating, and administrative reporting.

E-portfolios are stored online and have great accessibility for the portfolio owners themselves, teachers, colleagues, and employers (Bruder 1993; Bushweller 1995; McCowan et al. 2005). Eportfolios are a mechanism for students and education institutions to improve and demonstrate their teaching/learning skills and to display competencies to the society (Lumsden, Garis, Reardon, Unger, \& Arkin, 2001). E-portfolio systems enable administrations at all levels to survey and to conduct comprehensive assessment of teaching and learning accomplishments (Barrett 1994).

\section{E-Portfolio Artifacts are Learning Objects}

An e-portfolio artifact is a unit of digital resource that can be used to support learning, and thus is a learning object (Wiley \& Edwards, 2002). Along with the increasing use of e-learning systems, learning objects become increasingly valuable and, at the same time, the management of learning objects repository becomes complicated (Cohen \& Nycz, 2006; Collis \& Strijker, 2003; Singh, Hawkins, \& Whymark, 2007). There have been metadata standards for learning objects, such as those proposed by Dublin Core (DC, 2009), IEEE LTSC (IEEE LTSC, 2009), and IMS Guide (IMS, 2006), which is similar to library catalogue systems. However, to effectively use learning objects to support teaching and learning for a specific field, domain knowledge must be applied to manage the learning objects (Harman \& Koohang, 2005; Koohang, 2004; Mustaro \& Silveira, 2006). This has lead to approaches to Semantic Web applications that model the relationships between learning objects using formal ontologies (Sicilia \& Lytras, 2005).

Ontology techniques have been applied to repositories of learning objects (Namuth, Fritz, King, \& Boren, 2005; Smrz, 2004; Snae \& Brueckner, 2007; Wang, 2008; Zouaq Nkambou, \& Frasson, 2007). However, few research reports have discussed ontologies of e-portfolios for reflection and active thinking.

\section{Ontology Represents Structures of E-Portfolios}

Ontology is a science that studies explic it formal specifications of the terms in the domain and relations among them (Gruber, 1993). In the general philosophical term, an ontology is a specification of a conceptualization (Gruber, 1995). In the Semantic Web field, an ontology is typically 
a network of semantically related objects for a specific domain. An ontology allows people to share common understanding of the subject domain.

According to Resource Description Framework (RDF) (W3C, 2009), a primitive ontology is a triple containing a subject, an object, and a predicate (relationship) (see Figure 1a). Its special form that represents the reciprocal relationship between two learning objects (dual subject and object) is shown in Figure 1b. A large ontology for an entire doma in is a composition of a set of primitive ontologies. In this study, an ontology is a conceptual network of all related learning objects that shows the semantic relationships between the learning objects in the application domain.

Ontology is a powerful modeling approach; however, without a domain analys is for particular types of applications, the ontology approach remains a virtual philosophy, rather than a concrete technique for common understanding sharing (Devedzic, 2004). From the viewpoint of conceptual modeling theories, ontology is an object-oriented model for the application domain (Wang, 1999). To build ontologies based on the methodology progression, ontologies of e-portfolios must present the object-oriented vision. The task of a domain analysis for the construction of an ontology is to actualize classes of e-portfolio objects and their semantic relationships, as illustrated in the next section of this paper.

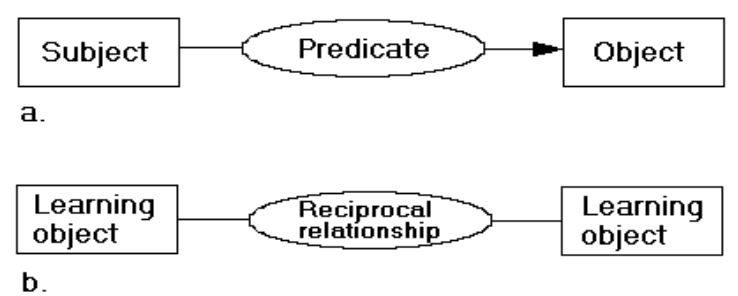

Figure 1: Primitive Ontology.

Research (Perkins, Jay, \& Tishman, 1993a, 1993b; Quillian 1968) has made connections between ontology and thinking that ontological expressions of domain specific knowledge and thinking processes can make signif icant contributions to teaching reflection. Although the real reflection activities in the human brain remain by and large an enigma, ontologies enable us to describe thinking routines (Ritchhart, 2002) for reflection process, and to make reflection visible as well as teachable.

\section{Ontological Categories of E-Portfolios Artifacts for Integrated Reflection}

To make ontologies sharable in a domain, it is important to categorize objects in the domain (Noy \& Hafner 1997). Categorizing e-portfolios artifacts can be helpful for the design of ontological structure of e-portfolio systems. The entire ontology of an e-portfolio system is usually large. To provide a large ontology visual and manageable to the user, the entire ontology must be partitioned. This is done through categorizing artifacts and developing the dynamic and inheritance relationships. A formalized generic category (or meta-learning-objects) of e-portfolios artifacts can help a community in developing and sharing its ontology, especially when the e-portfolio system is incorporated into a global learning system. However, in the broader literature, there is a lack of formal ontological description of e-portfolios artifacts. Next, we discuss generic eportfolios artifacts categories through a doma in analys is to identify and formalize fundamental types of artifacts and their relationships involved in integrated reflection.

\section{Learning Subject}

A learning subject is a meta-artifact that defines a discipline. It can have sub-subjects. A learning subject structure is a type of generalization structure. A typical order of the hierarchy of learning subjects for an e-portfolio system is: 
- College/School

- Program

- Course

- Topic.

A learning subject can have its attributes and descriptions. In the interdisciplinary context, a learning subject can inherit from multiple super-subjects. A topic is a primitive learning subject, and is associated with a learning objective directly.

\section{Learning Objective}

A learning objective is an artifact that describes a measurable learning outcome. Each learning subject retains its learning objectives. Bloom's taxonomy of education objectives (1956) is a framework that has been widely used in all disciplines. The original Bloom's framework includes six levels of learning: knowledge, comprehension, application, analys is, synthesis, and evaluation. Given the recent development in the knowledge management field, the term knowledge is no longer appropriate in this context. If knowledge and comprehension are merged into one level of learning, there are five levels of learning objectives as listed below.

- Understanding - know, define, identify, be aware of, etc.

- Application - apply, formulate, explain, etc.

- Analysis - analyze, organize, resolve, etc.

- Synthesis - design, plan, recommend, etc.

- Evaluation - justify, critic ize, evaluate, etc.

\section{Rubric}

A rubric specifies the criteria and standards for assessment, and is used to measure whether students have achieved the learning objectives. A rubric is usually a table. The rows of table list the criteria for the students' work (e.g., assignment, project, essay, etc.), and the columns of table list the assessment standards (e.g., excellent, very good, good, poor, etc.). Teachers assess students' work against the rubrics to maintain the uniformity of assessment. Samples of various rubrics can be found in (RUBRIC, 2009).

\section{Assessment Instrument}

An assessment instrument is a tool or technique to measure whether students have achieved the learning objectives. For instance, a test that contains quiz questions and/or questions for short answers is an assessment instrument to evaluate whether students understand the topic. An essay assignment or a textbook case analysis report is an assessment instrument for assessing students' analys is competency. A technical assignment is an assessment instrument to evaluating students' problem solving ability. A list of project requirements can be an assessment instrument to evaluate whether students have reached the evaluation learning objective. A student self-evaluation questionnaire can be an assessment instrument for soliciting students' opinions on an instructional method.

\section{Student Work}

Artifacts of student work are the major component of e-portfolios. Typical student work artifacts are:

- a reading report;

- an essay or reflection report;

- a case analysis report; 
- an assignment;

- a project report;

- an exhibit; and

- a test or examination.

In a broad view, less formal student's discussion notes in collaborative environment can also be artifacts of student work.

\section{Assessment Outcome}

An assessment outcome artifact is a documentation of learners' performance. At the elemental level, an assessment outcome artifact can be an individual learner's examination paper. At the collective level, a summary of assessment outcomes can be an artifact to measure the effectiveness of a course or program. In the educational literature the use of assessment outcomes to improve reflection is underreported. This is because traditional educational systems view the assessment outcome is the end of education, and do not store and utilize much assessment outcomes for iterative integrated reflection. Along with the proliferation of e-portfolio systems, massive assessment outcome artifacts are stored online. These artifacts provide valuable resources for teachers to teach integrated reflection as well as for students to learn integrated reflection.

\section{Reflection Dominant Model}

Reflection is a thinking process more than simple memorization and comprehension, and involves a variety of cognitive processes, such as summarization, identifying general principles, exploring various situations, reconciling options, monitoring progress, and so on. Although reflection emphasizes general thinking strategies and abilities across diverse situation, doma in-specif ic knowledge guides sophisticated reflection (Ericsson \& Smith, 1991).

Aram and Noble (1999) argue that the dominant models of learning and thinking are appropriate to the stable and predictable aspects of organizational life. To teach and learn integrated reflection, we need structured instruments or guidelines for reflection. Model is an important tool, if not the only one, that compels integrated reflection (Dunne \& Martin, 2006). While the ultimate models of reflection in great managers' mind might not be available, models can provide guidelines for integrated reflection. We refer models for teaching and learning integrated reflection to as reflection dominant models. For instance, the decision making model (Simon, 1976) taught in business can help students develop reflection dis positions of decision making. Students can apply this dominant model to any managerial decisions in all business subjects and think about the decision making processes as well as the important roles of data and information in decision making.

\section{Reflection Query}

A reflection dominant model can have questions, or reflection queries, for students to instigate reflection. A reflection query can be very general. For instance, the decision making dominant model can have generic reflection queries such as: How is the decision making model related to the cases you analyzed in many courses? Why were the decisions made in the cases you analyzed successful or failed in the view of the decision making model? How do you interpret variation to the standard decision making model? etc. A reflection query can also be specific to instigate reflection based on individual student's work.

Clearly, reflection dominant models are general tools or instruments for teaching and learning integrated reflection, and reflection queries are specific instructions which highly depending upon the teacher's analysis on students' reflective thinking. 


\section{Construction of an Ontological Structure of E-Portfolios for Reflection}

An ontology of e-portfolios for reflection is a synthesis of these eight categories (learning subject, learning objective, rubric, student work, assessment instrument, assessment outcome, reflection dominant model, and reflection queries) of e-portfolios artifacts on the contingency of teaching and learning integrated reflection. The synthesis process is to formalize the relationships between the e-portfolios artifacts of these categories. The premise of ontology is that generic semantics commonly exist among the objects that could be used for general purposes of navigation and search in the domain. In our case, these semantic relationships are used for general purposes of teaching and learning integrated reflection. For instance, in terms of inheritance relationships, a top-level Subject "has_a" low-level Subject. In terms of dynamic relationships, an Objective "uses" a Rubric. The generic dynamic semantic relationships between the e-portfolios learning objects are summarized in Figure 2. To focus more on integrated reflection, we choose the most relevant portion of the ontology, as shown by the shaded parts, for our case study of design of eportfolios structure for integrated reflection.

\section{Designing E-Portfolios for Integrated Reflection: A Case Study}

To learn more about ontological structure of e-portfolios for integrated reflection, a project was conducted to investigate the feasibility of design. We developed an ontological structure of eportfolios using the model discussed in the previous section (see the shaded part of Figure 2), and then implemented the structure on Chalk \& Wire ePortfolio2 (CW, 2009). Chalk \& Wire ePortfolio2 is a pioneer e-portfolio system which has been widely used in Canada, the United State, and other countries.

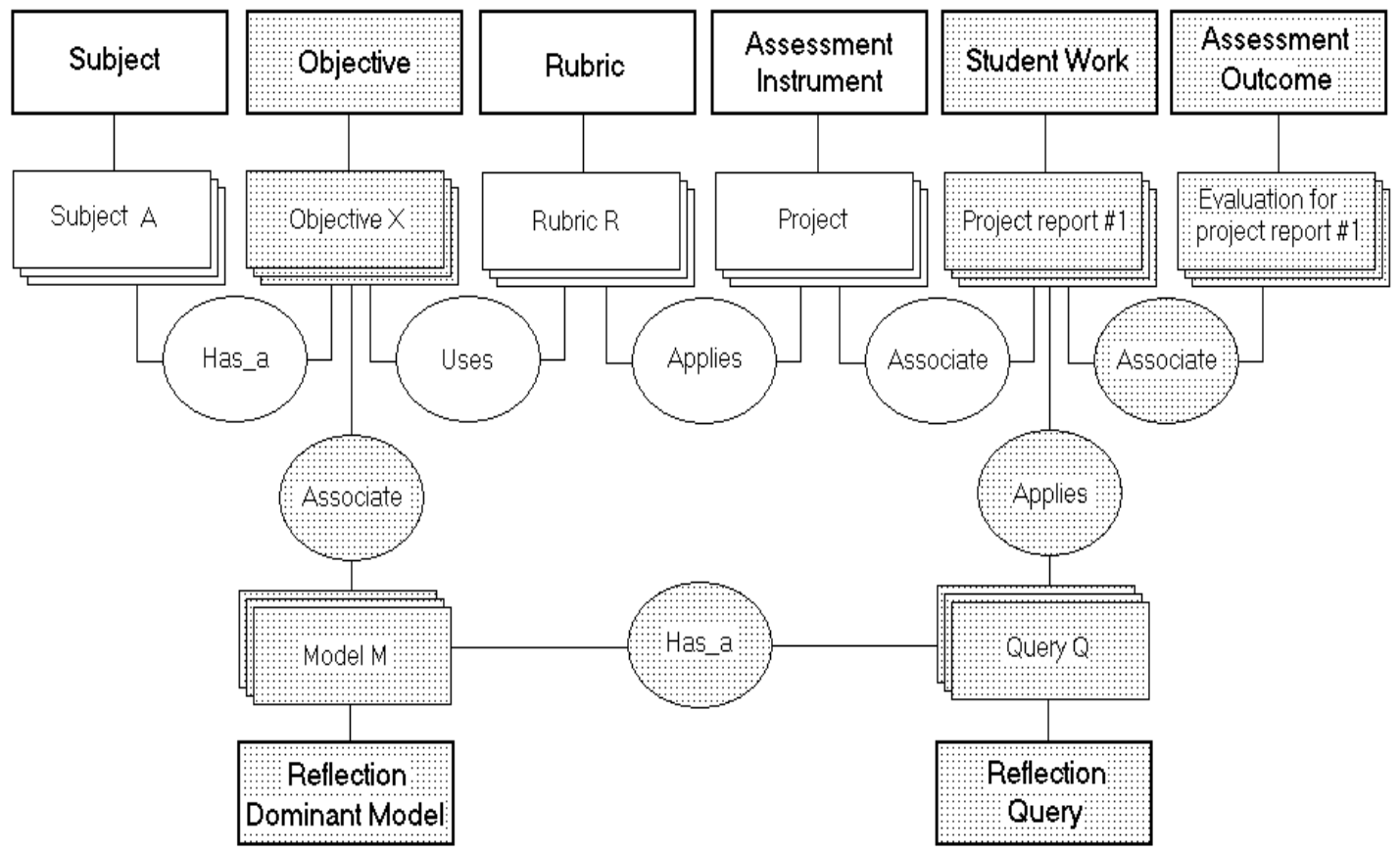

Figure 2: Ontology of E-Portfolios for Integrated Reflection. 


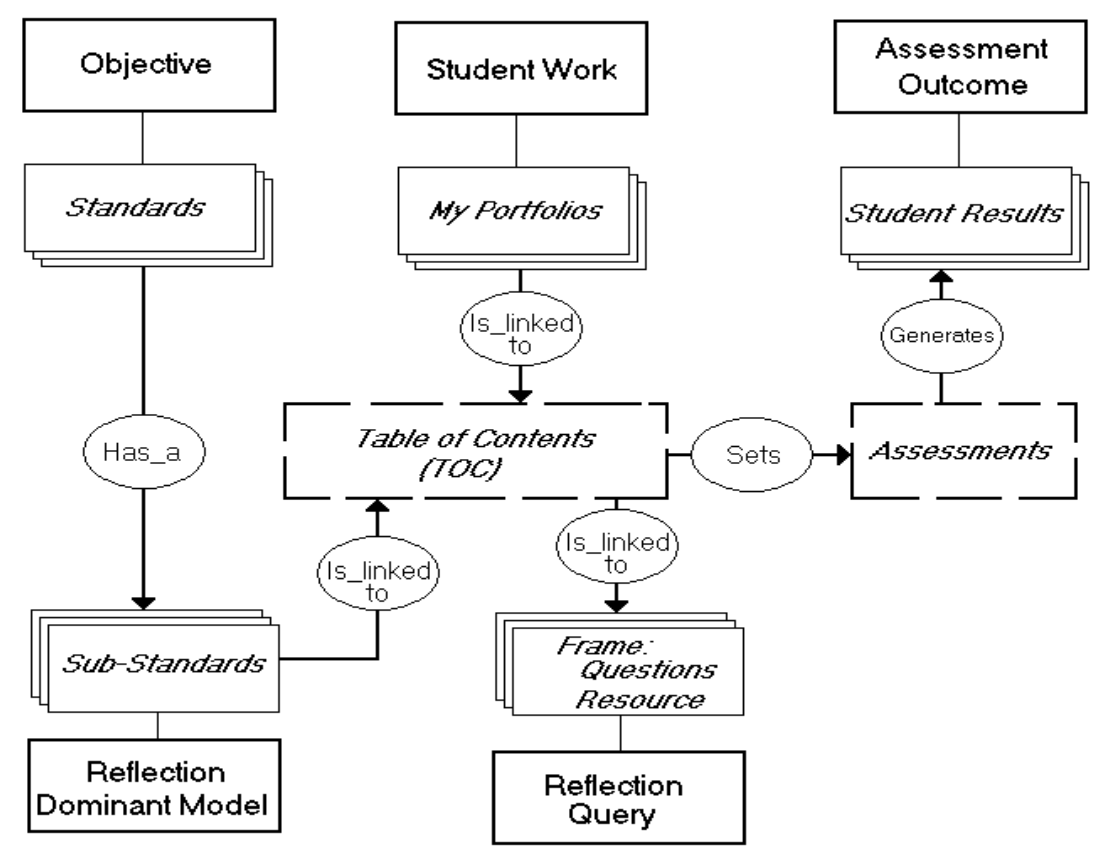

Figure 3. Ontologcial Structure of Re Think on Chalk \& Wire ePorfolios2 System.

We used the Chalk \& Wire ePortfolios 2 platform to implement a prototype of an extension shell, called ReThink, for integrated reflection. Figure 3 shows the inter-relational structure of the ontology at the top level of ReThink. We borrowed the artifact types of Chalk \& Wire ePortfolios2 (artifacts in Italic in Figure 3) for this shell. For instance, we used Sub-Standards of Chalk \& Wire ePortfolios 2 for reflection dominant models, My Porffolios for student work, etc. In addition, Chalk \& Wire ePortfolio2 has Table of Content (TOC) and Assessments. These two special types of artifacts are able to connect and generate the generic types of e-portfolio artifacts discussed in the previous section, as shown in Figure 3. We used the functions in TOC and Assessment to implement the semantic relationships between the e-portfolios artifacts for integrated reflection. Note that the Chalk \& Wire ePortfolio2 system must link a TOC to a Rubric(s). Although Figure 3 does not include Rubric in order not to dilute our emphasis on integrated reflection, one needs to create a rubric for a TOC in ReThink.

As an example, we present the features of the support of reflection in the learning subject of business. This is merely to demonstrate the approach to teaching and learning integrated reflection through the use of e-portfolios discussed above, but not for discussion of the pedagogical design which is a topic independent of this study. Figure 4 shows the creating of reflection dominant models through Sub-Standards in ReThink. Figure 5 shows the creating of reflection queries through Questions in Frame of TOC. One can also create reflection queries in Resource in Frame. The example in Figure 6 shows that the student was creating an e-portfolio artifact for a reflection assignment which was linked to the TOC. He was able to view the reflection queries for the reflection assignment. Once the student completed his reflection e-portfolio artifact, the TOC set Assessment for the teacher to generate Student Results as an assessment outcome.

The following primary lessons have been learned from the design of this prototype of shell. 


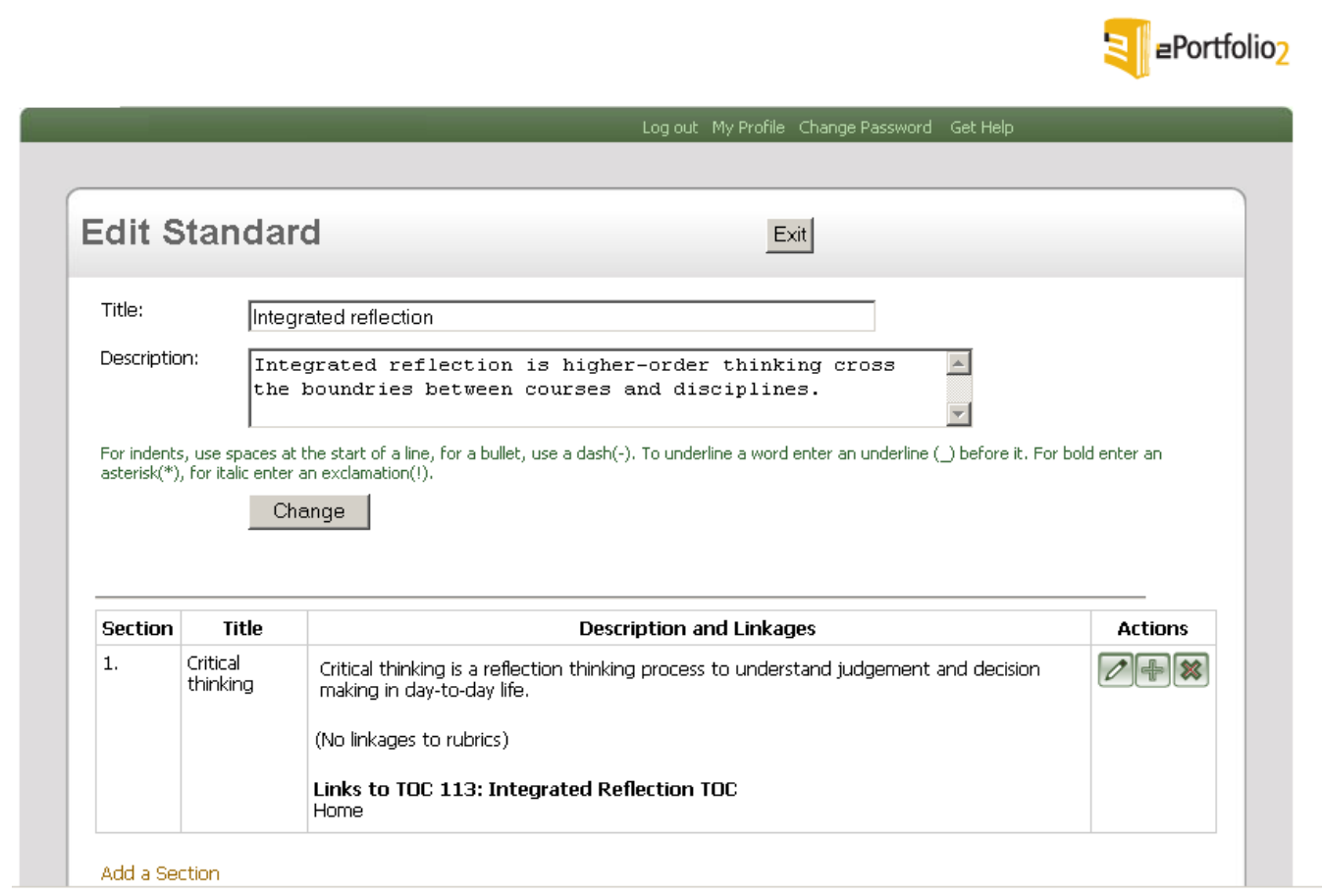

Figure 4: Creating Reflection Dominant Models through Standards.

(1) On the learning side, e-portfolios provide a perfect environment for students to view their portfolios online to learn what they have learned, and think about the way they think. For learning, the major difference between e-portfolios and online course-based teaching systems is that eportfolios shall be the source for the development of life-long learning ability cross the dimensions of time, courses, disciplines, and pos itions.

(2) On the teaching side, reflection dominant models and reflection queries are high-level information and codified know ledge of teaching reflection, and can be shared by the teaching community. This prototype has shown that e-portfolios can be an integrated teaching tool, which has not been widely implemented in the e-portfolios community.

(3) The ontology is a platform independent tool for system design. Individual e-portfolio system may have its own way to implement it, as demonstrated in our case study.

(4) Teaching and learning integrated reflection through e-portfolios is by no means at no cost. To connect an e-portfolio artifact to the ontology, one must define its relationships to other artifacts in accordance with the semantics defined by the ontology. The more relationships are defined, the better the e-portfolios are shared by the community.

To test a design of artifact like this prototype, rigorous independent experiments must be conducted to verify whether such an e-portfolio-based teaching tool is effective for integrated reflection. This case study has its limitation in that the ontological model and the prototype have not reached practical trials beyond the design experience. Clearly, while this study makes no claim to the validity of the proposed approach, it does offer an original idea of teaching and learning integrated reflection though the use of e-portfolios. This study has made its initial contribution to the accumulated weight of empirical evidence for establishing the validity of this approach. 


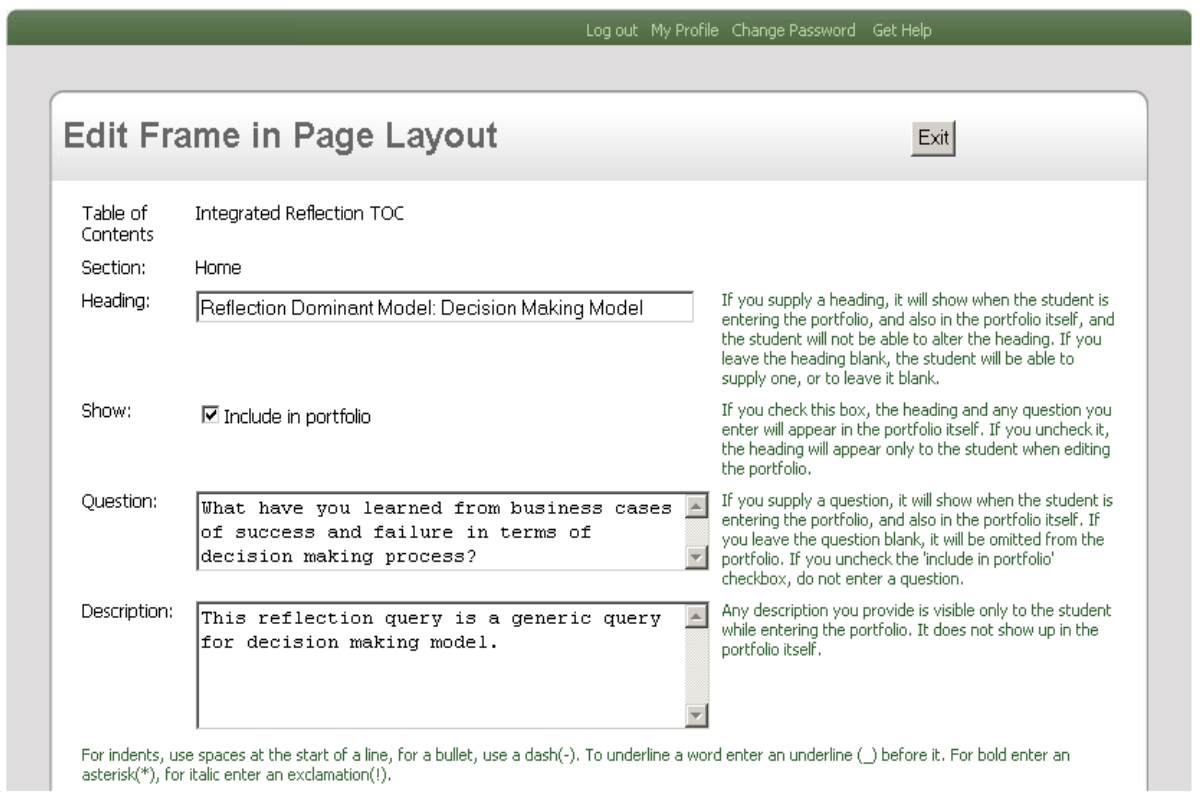

Figure 5. Creating Reflection Que ries in TOC Frame

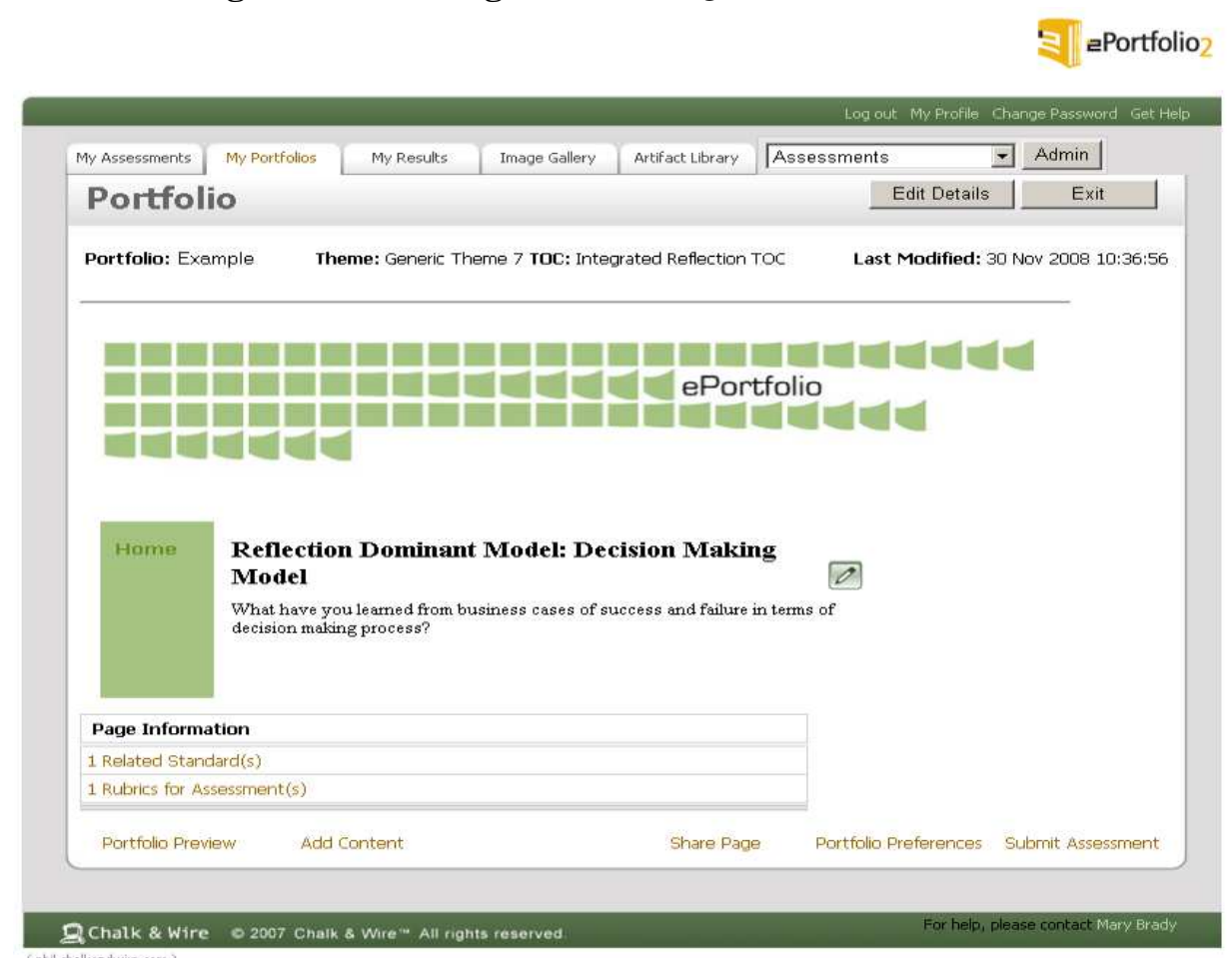

Figure 6: Creating a Reflection E-Portfolio Artifact

\section{Conclusion}

The competence of e-portfolios depends not only on the abundance of artifacts, but also the effectiveness of the use of e-portfolios for active learning. This paper recognizes a lack of applications of e-portfolios for integrated reflection beyond course-based teaching and assessment, and pro- 
poses a framework of ontological structure of e-portfolios for integrated reflection. The ontological model is based on the premise that integrated reflection is teachable through e-portfolios. The ontological model places the focal points on reflection dominant models and reflection queries, which are normally missing in e-portfolio applications. It adds explic it relationships between the e-portfolio artifacts that would make integrated reflection more visible. An ontology can be a teacher's teaching tool for teaching integrated reflection, or student's learning tool for active thinking cross the curricula. Technically, this study has primarily focused on the semantic aspects of e-portfolios for integrated reflection, and has shown the approach of e-portfolios to elearning.

As an example, we have implemented the ontological structure of e-portfolios through the use of Chalk \& Wire ePortfolio2. Our preliminary case study has shown new challenges for all parties involved in the e-portfolio community. For educational institutions, there is an organizational need to develop ontologies that contain semantic information about integrated reflection in various domains. The ontologies should be maintainable to represent the currency of integrated reflection. For e-portfolio systems developers, new techniques and tools are imperative to develop comprehensive uses of e-portfolios beyond assessment and showcase. In our view, the ontological model proposed here can practically be used for e-portfolio systems development. For teachers, new skills of teaching integrated reflection are required. They must clearly understand ontological structure of teaching integrated reflection, and transform unstructured reflection activities to structured tasks based on their own ontological structure of integrated reflection. For students, applications of e-portfolios for integrated reflection will be a new challenge of e-learning. In the long run, e-portfolios will be indisputable effective tool for active learning.

\section{Acknowledgement}

This study was supported by the CWScholars Grant Program of Chalk \& Wire Learning Assessment, Inc. Special thanks to Mr. Geoff Irvine and Ms. Gigi Devanney for their enthusiastic support. The comments of anonymous reviewers have contributed to the revision of the article.)

\section{References}

Aram, E. N., \& Noble, D. (1999). Educating prospective managers in the complexity of organizational life. Management Learning, 30(3), 321-342.

Barrett, H. C. (1994). Technology-supported asses sment portfolios. The Computing Teacher, 21, 9-12.

Bloom, B. S. (Ed.). (1956). Taxonomy of educational objectives: The classification of educational goals, Handbook I: Cognitive domain. New York: Long mans, Green.

Bruder, I. (1993). Alternative as sessment: Putting technology to the test. Electronic Learning, 12, 12-28.

Bushweller, K. (1995). The high-tech portfolio. The Executive Educator, 17, 19-22.

Cohen, E., \& Nycz, M. (2006). Learning objects e-learning: An informing science perspective. Interdisciplinary Journal of Knowledge and Learning Objects, 2, 23-24. Retrieved from http://ijello.org/Volu me2/v2p023-034Cohen32.pdf

Collis, B., \& Strijker, A. (2003). Re-usable learning objects in context. International Journal on ELearning, 2(4), 5-16.

CW. (2009). Chalk \& Wire. Retrieved February 4, 2009 from http://www.chalkandwire.com/eportfolio

DC. (2009). Dublin Core Metadata Initiative. Retrieved February 8, 2009 fro m http://dublincore.org

Devedzic, V. (2004). Education and the semantic web. International Journal of Artificial Intelligence in Education, 14, 39-65.

Drier, H. N. (1997). Career portfolios - Don't leave home without one. Career Planning \& Adult Development Journal, 12(4), 55-60. 
Dunne, D., \& Martin, R. (2006). Design thinking and how it will change management education: An interview and discussion. Academy of Management Learning \& Education, 5(4), 512-523.

Ericsson, K. A., \& Smith, J. (1991). Toward a general theory of expertise: Prospects and limits. Cambridge, UK: Cambridge University Press.

Foliotek. (2009). foliotek e-portfolio system. Retrieved February 5, 2009 from http://www.foliotek.co m/

Greenberg, G. (2004). The digital convergence: Extending the portfolio. Educause Review, 39(4), 28-36.

Gregor, S. (2006). The nature of theory in information systems. MIS Quarterly, 30(3), 611-635.

Gregor, S., \& Jones, D. (2007). The anatomy of a design theory. Journal of the Association for Information Systems, 8(5), Article 2.

Gruber, T. (1993). A translation approach to portable ontology specifications. Knowledge Acquisition, 5(2), 199-220.

Gruber, T. (1995). Toward princip les for the design of ontologies used for knowledge sharing. International Journal of Human and Computer studies, 43(5/6), 907-928.

Harman, K., \& Koohang, A. (2005). Discussion board: A learn ing object. Interdisciplinary Journal of Knowledge and Learning Objects, 1, 67-77. Retrieved fro m http://ijello.org/Volu me 1/v1p067077Harman.pdf

Hevner, A. R., March, S. T., Park, J. \& Ram, S. (2004). Design science in information system research. MIS Quarterly, 28(1), 75-105.

IEEE LTSC. (2009). IEEE Learning Technology Standards Committee. Retrieved February 15, 2009 from http://ieeeltsc.org

IMS. (2006). IMS Meta-data Best Practice Guide for IEE 1484.12.1-2002 Standard for Learning Object Metadata Version 1.3 Final Specification. Retrieved February 13, 2009, from http://www.imsproject.org/metadata/

KEEP. (2009). KEEP toolkit. Retrieved February 15, 2009 fro m http://www.cfkeep.org/static/index.html

Koohang, A. (2004). Creating learning objects in collaborative e-learning settings. Issues in Information Systems, 4(2), 584-590.

Lumsden, J. A., Garis, J. W., Reardon, R. C., Unger, M. P., \& Arkin, S. (2001). A blueprint for building an online career portfolio. Journal of Career Planning and Employment, 62(1), 33-38.

McCowan, C., Harper, W. \& Hauville, K. (2005). Student e-portfolio: The successful implementation of an e-portfolio across a major Australian university. Australian Journal of Career Development, 14(2), 4052.

Mustaro, P. N., \& Silveira, I. F. (2006). Learning objects: Adaptive retrieval through learning styles. Interdisciplinary Journal of Knowledge and Learning Objects, 2, 35-46. Retrieved from http://ijello.org/Volu me2/v2p035-046Mustaro.pdf

Namuth, D., Fritz, S., King, J. \& Boren, A. (2005). Principles of sustainable learning object libraries. Interdisciplinary Journal of Knowledge and Learning Objects, 1, 181-196. Retrieved from http://ijello.org/Volu me 1/v1p181-196Namuth.pdf

Noy, N. F., \& Hafner, C. D. (1997). The state of the art in ontology design. AI Magazine, 18(3), 53-74.

OSP. (2005). Open-Source Portfolio, White paper: Understanding OSP. Retrieved February 15, 2009 from http://www.rsmart.com/assets/understandingOSP Dec2005.pdf

Perkins, D., Jay, E. \& Tishman, S. (1993a). Introduction: New conceptions of thinking. Educational Psychologist, 28(1), 1-5.

Perkins, D., Jay, E. \& Tishman, S. (1993b). New conceptions of thinking: Fro m ontology to education. Educational Psychologist, 28(1), 67-85.

Quillian, R. (1968). Semantic memory. In M. Minsky (Ed.), Semantic information processing. Cambridge, MA: MIT Press.

RUBRIC. (2009). Sample of rubrics. Retrieved February 16, 2009 from http://school.discoveryeducation.com/s chrockguide/ass ess.html 
Ritchhart, R. (2002). Intellectual character: What it is, why it matters, and how to get it. San Francisco, CA: Jossey Bass.

Sicilia, M. A., \& Lytras, M. (2005). On the representation of change according to different ontologies of learning. International Journal of Learning and Change, 1(1), 66-79.

Simon, H. A. (1976). Administrative behavior ( $3^{\text {rd }}$ ed.). New York: The Free Press.

Singh, G., Hawkins, L., \& Why mark, G. (2007). An integrated model of collaborative knowledge building. Interdisciplinary Journal of Knowledge and Learning Objects, 3, 85-105. Retrieved from http://ijello.org/Volu me3/IJKLOv3p085-105Singh385.pdf

Smrz, P. (2004). Integrating ontologies into learning manage ment systems - A case of Czech. In R. Meersman, Z. Tari, \& A. Corsaro, OTM Workshops, LNCS 3292, 768-772.

Snae, C., \& Brueckner, M. (2007). Ontology-driven e-learning system based on roles and activities for Thai learning environ ment. Interdisciplinary Journal of Knowledge and Learning Objects, 3, 1-17. Retrieved fro $\mathrm{m}$ http://ijello.org/Volu me3/IJKLOv3p001-017Snae.pdf

TaskStream. (2009). TaskStream e-portfolio system. Retrieved February 12, 2009 from https://www.taskstream.com/pub/

W3C. (2009). World Wide Web Consortium. Retrieved February 8, 2009 from http://www.w3.org/

Walls, J. G., W idmeyer, G. R., \& El Sawy, O. A. (1992). Build ing an information design theory for vigilant EIS. Information Systems Research, 3(1), 36-59.

Wang, S. (1999). Analyzing business information systems: An object-oriented approach. Boca Raton, FL: CRC Press.

Wang, S. (2008). Ontology of learning objects repository for educational knowledge sharing. Interdisciplinary Journal of Knowledge and Learning Objects, 4, 2008, 1-12. Retrieved from http://ijello.org/Volu me4/IJKLOv4p001-012Wang200.pdf

Wiley, D. A., \& Edwards, E. K. (2002). On line self-organizing social systems: The decentralized future of online learning. Quarterly Review of Distance Education, 3(1), 33-46.

Zhang, S. X., Olfman, L., \& Rectham, P. (2007). Designing eportfolio 2.0: Integrating and coordinating web 2.0 services with eportfolio systems for enhancing users' learning. Journal of Information Systems Education, 18(2), 203-214.

Zouaq, A., Nkambou, R., \& Frasson, C. (2007). An integrated approach for automatic aggregation of learning knowledge objects. Interdisciplinary Journal of Knowledge and Learning Objects, 3, 135-162. Retrieved from http://ijello.org/Volu me3/IJKLOv3p 135-162Zouaq.pdf

\section{Biography}

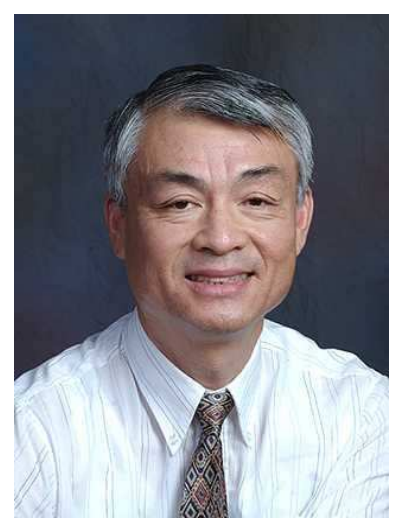

Shouhong Wang is a Professor of MIS in the Department of Decision and Information Sciences at University of Massachusetts Dartmouth. He received his Ph.D. in Information Systems from McMaster University, Canada. His research interests include e-portfolios and learning objects repository design. He has published over 90 papers in academic journals, including Journal of Information Technology Education, Interdisciplinary Journal of Knowledge and Learning Objects, Journal of Information Systems Education, Journal of Management Information Systems, Information \& Management, International Journal of Information Management, IEEE Transactions on Systems, Man, and Cybernetics, Management Science, Decision Sciences, IEEE Transactions on Patter Analysis and Machine Intelligence, Journal of The Operational Research Society, OMEGA, INFORMS Journal on Computing, Information Resources Management Journal, INFOR, Knowledge and Information Systems, Journal of Organizational and End User Computing, and others. 